\title{
Between-laboratory comparison of densitometry and bio-electrical impedance measurements
}

\author{
BY PAUL DEURENBERG \\ Department of Human Nutrition, Wageningen Agricultural University, Bomenweg 2, \\ 6703 HD Wageningen, The Netherlands \\ AND KLAAS R. WESTERTERP \\ Department of Human Biology, University of Limburg, PO Box 616, 6200 MD Maastricht, \\ The Netherlands \\ AND ERICA J. M. VELTHUIS-TE WIERIK \\ TNO-Toxicology and Nutrition Institute, PO Box 360, 3700 AJ Zeist, The Netherlands
}

(Received 5 January 1993 - Revised 22 April 1993-Accepted 20 May 1993)

\begin{abstract}
Body composition was measured in nine healthy, normal-weight, weight-stable subjects in three different research centres. In each centre the usual procedures for the measurements were followed. It revealed that the measurement procedures in the three centres were comparable. Body composition was measured in each centre between 09.00 and 13.00 hours after a light breakfast by densitometry (underwater weighing) and bio-electrical impedance. A single, total-body-water determination by $\mathrm{D}_{2} \mathrm{O}$ dilution was used as a reference value. Body fat determined by densitometry was significantly lower in one centre, which, however, could be completely explained by a lower body weight, probably due to water loss (the subjects refrained for a longer time from food and drinks before the measurements in that centre) and, thus, by violation of the assumptions of Siri's (1961) formula. Also, body impedance was slightly higher in that centre, indicating a lower amount of body water. Mean body fat from densitometry was also slightly lower in that centre compared with body fat determined by $\mathrm{D}_{2} \mathrm{O}$ dilution. Individual differences between body fat from densitometry and from total body water were relatively large, up to $7 \%$ body fat. The relationship between fat-free mass from densitometry and bio-electrical impedance was not different between the centres. It is concluded that differences in the relationship between body composition and bio-electrical impedance, as reported in the literature, may be due to differences in standardization procedures and/or differences in reference population.
\end{abstract}

Body composition: Densitometry: Bio-electrical impedance

The assessment of body composition is important as an indicator of the nutritional status of a subject or a group (Moore et al. 1963; Forbes, 1987; Lukaski, 1987). Depending on the subjects and the circumstances, several aspects of body composition can be assessed for which, generally, several methods are available. Although in recent years new information has been made available by the use of modern techniques such as neutron-activation and computer tomography-scanning, most of the generally- and widely-used methods are still based on the results of the chemical analysis of a few human cadavers (Widdowson et al. 1951). From these chemical analyses three basic methods have been derived which have been accepted as reference methods. These are the densitometric method, the dilution method for total body water, and the ${ }^{40} \mathrm{~K}$ method (Forbes, 1987). Each of these methods has its own assumptions, which are in fact only valid for healthy adults at a group level and which are known to be invalidated in many other groups of subjects (Slaughter et al. 1988; 
van Raaij et al. 1989; Weststrate \& Deurenberg, 1989; Deurenberg et al. 1989 a, c). From the reference methods many 'indirect', in fact 'double indirect', methods were developed, such as skinfold thickness measurements (Durnin \& Womersley, 1974) and impedance analysis (Lukaski et al. 1985).

Numerous studies have been published in which several methods are compared, crosssectional (Blanchard et al. 1990; McNeill et al. 1991; Tagliabue et al. 1992) as well as longitudinal (Van der Kooy et al. 1992).

To our knowledge there have been no studies in which a comparison has been made between results from different laboratories using the same subjects and the same methods. This might be due to logistical problems. In The Netherlands we have three centres at which body composition can be measured by both a reference method (densitometry by underwater weighing) and by impedance analysis, and the travelling distances between these centres are relatively small. Therefore, a study was performed to investigate whether there are differences in results when the same subjects are assessed by the same method in different laboratories.

\section{SUBJECTS AND METHODS}

Nine subjects, seven females and two males, aged 22-55 years participated in the study. They had all had previous experience with the methods used as they had participated in several studies on body composition. Some physical characteristics of the subjects are given in Table 1. The three centres in which the body composition measurements were performed were the Department of Human Nutrition in Wageningen (centre A), the Department of Human Biology in Maastricht (centre B), and the TNO-Toxicology and Nutrition Institute in Zeist (centre C). The distance between the centres is $1-3 \mathrm{~h}$ drive by car.

All measurements were done in the morning between 09.00 and 13.00 hours, at least $2 \mathrm{~h}$ after a light breakfast. The measurements in four subjects were performed within $3 \mathrm{~d}$, in three subjects within $6 \mathrm{~d}$ and in two subjects within $10 \mathrm{~d}$. Body height was measured using a microtoise to the nearest $0.001 \mathrm{~m}$. In all three centres body weight was measured in a swimsuit to at least the nearest $0.1 \mathrm{~kg}$ using a digital scale. Body impedance was measured at the left side of the body at a frequency of $50 \mathrm{KHz}$. In two centres a Xitron 4000 (Xitron Technologies, San Diego, CA, USA) impedance analyser was used, and in one centre (C) a RJL BIA 101 impedance analyser (RJL-systems, Detroit, MI, USA). The current injection electrodes were placed on the dorsal surfaces of hand and foot. The voltage drop was measured with electrodes placed between the distal prominences of the radius and the ulna and lateral malleoli at the ankle. Impedance was calculated as (resistance $^{2}+$ reactance $\left.^{2}\right)^{0.5}$. The measurements were performed in duplicate. Body density was determined by underwater weighing, with simultaneous determination of the residual lung volume (accuracy 0.1 litres). In each centre the He dilution technique (Comroe et al. 1977) was used. The instruments were obtained from different companies but had comparable specifications. In two centres the underwater weight was measured with a digital scale to the nearest $1 \mathrm{~g}$; in the other centre (C) the underwater weight was measured with an analogue scale. The accuracy of a reading in that centre was about $50 \mathrm{~g}$. The mean value of two underwater weighing measurements (and two residual lung volumes) was used for the calculation of body density. From body density percentage body fat was calculated using Siri's (1961) formula.

Total body water was determined by $\mathrm{D}_{2} \mathrm{O}$ dilution. The measurements were done on the same morning as the underwater weighing and impedance measurements in centre A. After a light breakfast and after voiding (background urine sample for $\mathrm{D}$ ), a dose of $0.08 \mathrm{~g} \mathrm{D}_{2} \mathrm{O}$ $\left(99.8 \% \mathrm{D}_{2} \mathrm{O}\right) / \mathrm{kg}$ fat-free mass (FFM) was taken orally. After a 3 and $4 \mathrm{~h}$ dilution time a urine sample was collected. The D concentration in background and $4 \mathrm{~h}$ urine was 
Table 1. Age and physical characteristics of the subjects*

(Mean values and standard deviations for nine subjects, seven females, 2 males)

\begin{tabular}{lcc}
\hline \hline & Mean & SD \\
\hline Age (years) & $28 \cdot 2$ & $12 \cdot 1$ \\
Body wt $(\mathrm{kg})$ & $67 \cdot 1$ & $8 \cdot 1$ \\
Height $(\mathrm{m})$ & $1 \cdot 73$ & 0.08 \\
Body mass index $\dagger\left(\mathrm{kg} / \mathrm{m}^{2}\right)$ & $22 \cdot 3$ & $1 \cdot 8$ \\
\hline \hline
\end{tabular}

* Values as measured in centre A (see p. 310).

$\dagger$ Weight/height ${ }^{2}$.

determined with an Aqua-Sira mass spectrometer (VG Isogas Ltd, Middlewich, Cheshire). From the difference in D concentration in urine before and after the dose, the amount of total body water (TBW) was calculated (Forbes, 1987). A correction for $40 \mathrm{~g} / \mathrm{kg}$ nonaqueous dilution was used (Schoeller et al. 1980). FFM was calculated from TBW using a hydration factor of 0.73 (Forbes, 1987). Fat mass (FM) was calculated as the difference between body weight and FFM. Percentage body fat was calculated as FM/body weight. The percentage body fat derived from $\mathrm{D}_{2} \mathrm{O}$ dilution was used as a relative standard.

Statistical calculations were performed with the SPSS-PC package (SPSS, 1988). The relation between FFM and impedance was analysed in each centre by linear regression. Differences in variables between centres were tested by ANOVA (repeated measurements) techniques. Differences in variables within each centre were tested by the paired Student's $t$ test. A level of significance of $P<0.05$ was accepted. Correlations are Pearson's productmoment correlations. The Bland \& Altman (1986) procedure was used to assess the relative validity of measurements. Body fat determined by $\mathrm{D}_{2} \mathrm{O}$ dilution was used as the standard. Values are expressed as means and standard deviations.

\section{RESULTS}

Physical characteristics of the subjects are shown in Table 1, and body weight, body density and impedance as measured in each centre are given in Table 2. Centre B showed significant differences in body weight, body density, fat mass and fat-free mass compared with centres $\mathrm{A}$ and $\mathrm{C}$. The differences are more pronounced between centres $\mathrm{A}$ and $\mathrm{B}$. These differences remained when only the data for the seven females were used in the analysis. When the percentage body fat determined by underwater weighing was compared with body fat from $\mathrm{D}_{2} \mathrm{O}$ dilution centre $\mathrm{B}$ showed a significantly lower percentage body fat (Table 3 ). Table 4 gives the Pearson's product-moment correlation coefficient for the percentage body fat between each centre together with the correlation with the body fat from deuterium oxide dilution. Fig. 1 shows the difference in percentage body fat determined by underwater weighing and $\mathrm{D}_{2} \mathrm{O}$ dilution $v$. the percentage body fat by $\mathrm{D}_{2} \mathrm{O}$ dilution. Although the mean differences as given in Table 3 were relatively small, individual differences were up to $7 \%$ body fat. There were no striking differences between males and females. Table 4 gives the correlation coefficient between percentage body fat by $\mathrm{D}_{2} \mathrm{O}$ dilution and by densitometry in each centre.

The prediction equations for FFM from height ${ }^{2} /$ impedance did not differ significantly in intercept and slope between the centres (results not shown). Table 5 gives the difference in FFM as determined by underwater weighing and the FFM as predicted from impedance, when using the prediction equations based on the data measured in each centre. 
Table 2. Body composition variables as determined at each of the three centres for the same subjects $\dagger$

(Mean values and standard deviations for nine subjects)

\begin{tabular}{|c|c|c|c|c|c|c|}
\hline \multirow[t]{2}{*}{ Centre... } & \multicolumn{2}{|c|}{ A } & \multicolumn{2}{|c|}{ B } & \multicolumn{2}{|c|}{ C } \\
\hline & Mean & SD & Mean & SD & Mean & SD \\
\hline Body wt (kg) & $67 \cdot 1$ & $8 \cdot 1$ & $66 \cdot 6^{*}$ & $7 \cdot 9$ & $67 \cdot 3$ & $8 \cdot 2$ \\
\hline Body density $(\mathrm{kg} / \mathrm{l})$ & $1 \cdot 0383$ & 0.012 & $1.0436^{*}$ & 0.014 & 1.0418 & 0.010 \\
\hline Body impedance (ohms) & 565 & 93 & 572 & 99 & 567 & 102 \\
\hline Percentage body fat $\ddagger$ & $26 \cdot 2$ & $7 \cdot 1$ & - & - & - & - \\
\hline Percentage body fat $\S$ & $26 \cdot 8$ & $5 \cdot 6$ & $24 \cdot 4^{*}$ & $6 \cdot 2$ & $25 \cdot 2$ & $4 \cdot 7$ \\
\hline Fat-free mass $(\mathrm{kg}) \S$ & $49 \cdot 2$ & $8 \cdot 3$ & $50 \cdot 5^{*}$ & $8 \cdot \overline{3}$ & $50 \cdot 4$ & $7 \cdot 7$ \\
\hline
\end{tabular}

Mean values were significantly different from those for the other two centres (ANOVA): ${ }^{*} P<0 \cdot 05$.

$\dagger$ For details of subjects and procedures, see Table 1 and pp. $310-311$.

From deuterium oxide dilution.

$\$$ By densitometry.

Table 3. Difference in percentage body fat derived from deuterium oxide dilution and by densitometry at each of the three centres for the same subjects $\$$

(Mean values and standard deviations for nine subjects)

\begin{tabular}{cccc}
\hline \hline Centre & Mean & SD & Range \\
\hline A & $-0 \cdot 6$ & $1 \cdot 7$ & $-3 \cdot 2-+2 \cdot 1$ \\
B & $+1 \cdot 8^{*}$ & $1 \cdot 7$ & $-1 \cdot 4-3 \cdot 7$ \\
C & $+1 \cdot 0$ & $3 \cdot 7$ & $-5 \cdot 4-+7 \cdot 5$ \\
\hline
\end{tabular}

Mean values were significantly different from those for the other two centres (paired $t$ test): ${ }^{*} P<0.05$.

$\dagger$ For details of subjects and procedures, see Table 1 and pp. 310-311.

$\ddagger$ Body fat from total body water minus body fat from densitometry.

Table 4. Pearson's product-moment correlation coefficients between body fat (fat \%) derived by densitometry and body fat obtained by deuterium oxide dilution at each of the three centres $(A, B, C)$ for the same subjects* ${ }^{*}$

\begin{tabular}{ccccc}
\hline \hline & \multicolumn{5}{c}{ Fat \% } \\
\cline { 2 - 5 } Fat \% & $\mathrm{D}_{2} \mathrm{O}$ & $\mathrm{A}$ & $\mathrm{B}$ & $\mathrm{C}$ \\
\hline $\mathrm{D}_{2} \mathrm{O}$ & - & 0.99 & 0.98 & 0.88 \\
$\mathrm{~A}$ & - & - & 0.97 & 0.87 \\
$\mathrm{~B}$ & & & - & 0.90 \\
\hline
\end{tabular}

* All values were significant $(P<0.01)$

$\dagger$ For details of subjects and procedures, see Table 1 and pp. 310-311.

\section{DISCUSSION}

Many studies describe the comparison between different methods of body composition measurements (Blanchard et al. 1990; McNeill et al. 1991; Tagliabue et al. 1992; Van der Kooy et al. 1992). To our knowledge, however, no study has yet been focused on possible differences when the same subjects are measured in different laboratories. This may be 
(a) Data from centre A
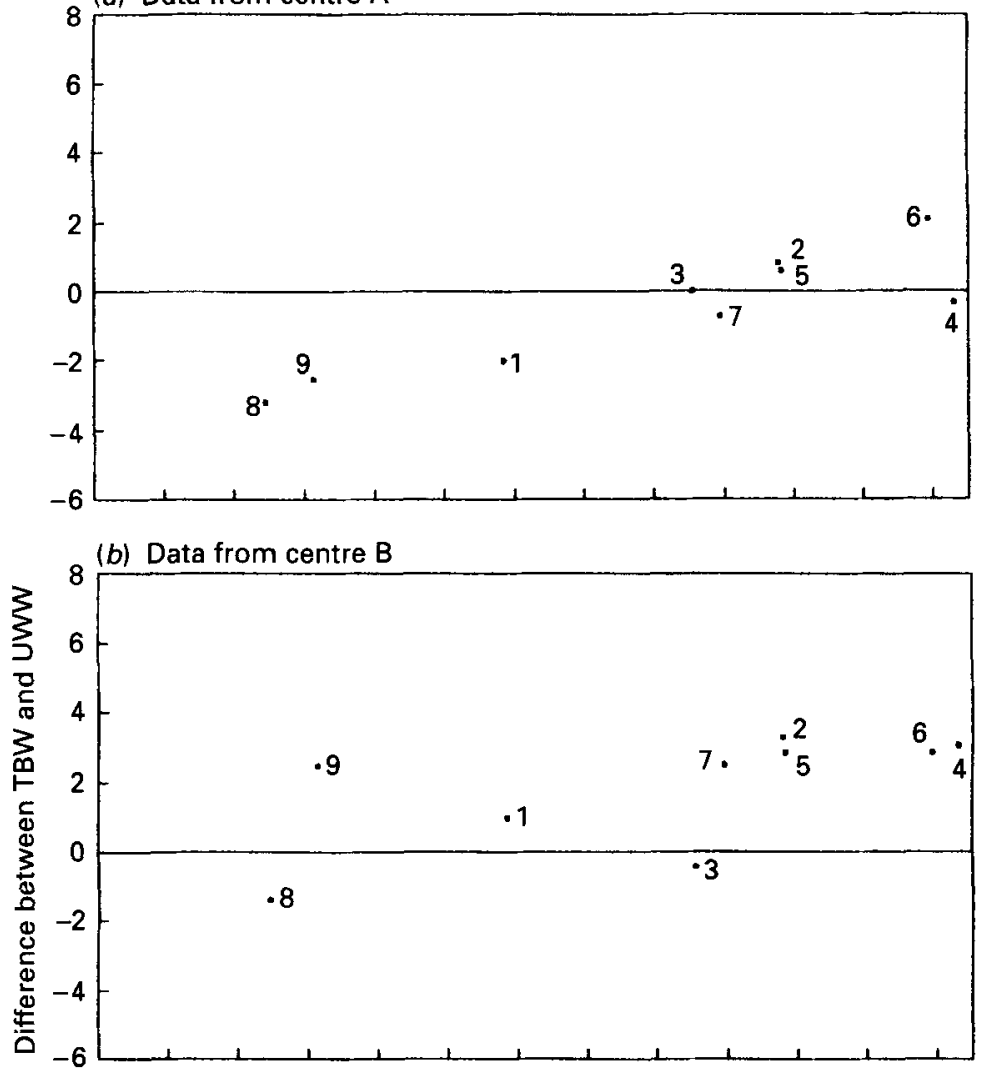

(c) Data from centre C

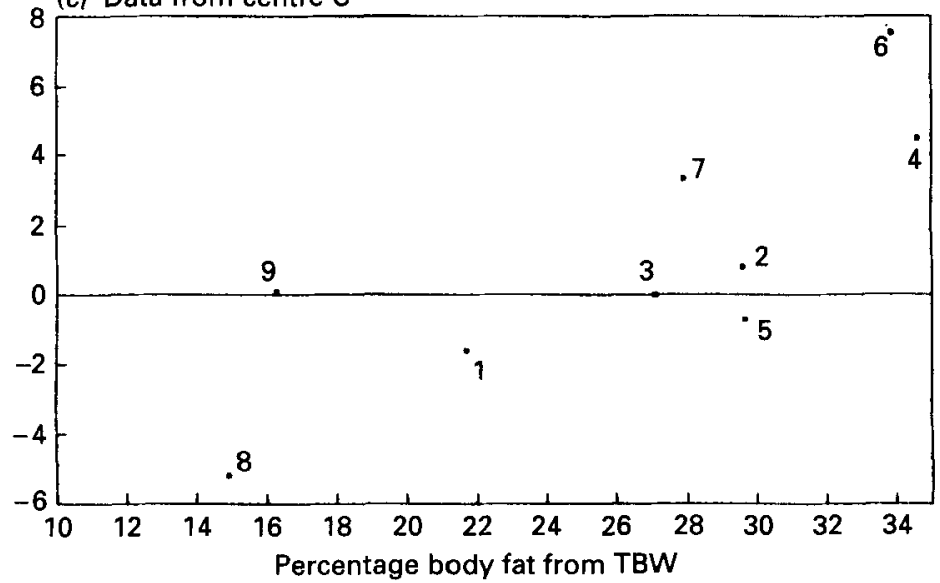

Fig. 1. Individual differences between percentage body fat estimated from deuterium oxide dilution and densitometry at each of the three centres for the same subjects. Difference = body fat from total body water minus body fat from densitometry. For details of subjects and procedures, see Table 1 and pp. $310-311$. Subjects nos. 8 and 9 were male, nos. 1-7 were female. 
Table 5. Measured fat-free mass (FFM; $k g$; by underwater weighing) and predicted FFM ( $\mathrm{kg} ;$ by impedance) using centre-specific prediction formulas for each of the three centres and the same subjects $\dagger$

(Mean values and standard deviations for nine subjects)

\begin{tabular}{|c|c|c|c|c|c|c|c|c|}
\hline \multirow{2}{*}{\multicolumn{3}{|c|}{$\begin{array}{c}\text { Measured FFM } \\
\text { at centre }\end{array}$}} & \multicolumn{6}{|c|}{ Difference in predicted FFM with formula from centref } \\
\hline & & & \multicolumn{2}{|c|}{ A } & \multicolumn{2}{|c|}{ B } & \multicolumn{2}{|c|}{$\mathrm{C}$} \\
\hline & Mean & SD & Mean & SD & Mean & $\mathrm{SD}$ & Mean & SD \\
\hline A: & $49 \cdot 2$ & $8 \cdot 3$ & \multicolumn{2}{|c|}{ - } & $-1 \cdot 5^{*}$ & 1.9 & $-1 \cdot 1$ & $2 \cdot 3$ \\
\hline B: & $50 \cdot 5$ & $8 \cdot 3$ & $1 \cdot 5$ & $2 \cdot 4$ & \multicolumn{2}{|c|}{-} & 0.4 & $2 \cdot 5$ \\
\hline $\mathrm{C}:$ & $50 \cdot 4$ & $7 \cdot 7$ & $1 \cdot 1$ & $2 \cdot 8$ & -0.4 & $2 \cdot 6$ & \multicolumn{2}{|c|}{-} \\
\hline
\end{tabular}

Mean value was significantly different from those for the other two centres: ${ }^{*} P<0.05$.

$\dagger$ For details of subjects and procedures, see Table 1 and pp. 310-311.

$\ddagger$ Measured minus predicted.

attributable to logistical problems. In The Netherlands we have at relatively close proximity three centres where body composition measurements are carried out regularly, using several techniques. Therefore, the present study describes the between-laboratory comparison of body composition measurements in the same subjects.

At each centre the measurements were carried out in their usual way, without any discussion beforehand on standardization. In each institute all instruments were calibrated as usual. It appeared that there were no differences in the placement of the electrodes during the impedance measurements. Table 2 shows that there were slight and sometimes significant differences in the mean values of measured body composition between the three centres; centre B tended to have lower values for percentage body fat, fat mass and body weight and higher values for FFM. These lower values could be explained completely, however, by the fact that the measurements in centre B took place about $2-3 \mathrm{~h}$ later in the morning compared with the measurements in centres $\mathrm{A}$ and $\mathrm{C}$. The subjects refrained from eating and drinking during that time. Thus, loss of body water could be the reason for the lower body weight. The water loss will also have caused an increase in the density of the FFM (Forbes, 1987). Using Siri's (1961) equation under these conditions will result in a lower estimate for percentage body fat. Also, the slightly higher mean impedance value indicates a lower body water content during the measurements at centre B. Individually the differences between the centres were sometimes large.

The data in Tables 3 and 4 and in Fig. 1 show that the variation between the centres in percentage body fat derived by densitometry compared with $\mathrm{D}_{2} \mathrm{O}$ dilution was large, especially for centre $C$. This shows that an accurate measurement of the underwater weight is absolutely essential. An accuracy in the underwater weighing of 50-100 g, as occurred in centre $C$, seems not to be appropriate. This is indicated also by the approximately fivefold larger variability in the duplicate measurements of the body density at centre $\mathrm{C}$ compared with centres $\mathrm{A}$ and $\mathrm{B}$ (results not shown). The significant difference in body fat derived from total body water and density at centre B may, as discussed previously, again be the result of invalidating the assumptions for Siri's (1961) formula. The relatively low difference between body fat derived by densitometry and body fat obtained by $\mathrm{D}_{2} \mathrm{O}$ dilution at centre A may be due to the fact that both techniques were performed on the same morning.

When 'centre-specific' prediction formulas were calculated from impedance and the FFM (as determined by underwater weighing; FFM $=a \times$ height $^{2} /$ impedance $+b$ ), these 
formulas did not differ in slope and intercept (results not shown). Applying these 'centrespecific' prediction formulas to the data measured at the other centres revealed slight differences in predicted mean FFM up to $1.5 \mathrm{~kg}$ (Table 5). Larger differences between measured FFM and predicted FFM using prediction formulas from the literature are reported by several authors (Deurenberg et al. 1991; Svendson et al. 1991). The present study shows that prediction formulas developed at different institutes for the same subjects reveal the same results. In the present study there were no apparent differences in placements of electrodes, which has a large impact on the measured impedance value (Baumgartner et al. 1989; Scheltinga et al. 1991), and the differences in reference value (FFM by underwater weighing) were only small but significant. Although these differences could be explained completely by the longer duration of the fasting state for subjects measured at centre $\mathrm{B}$, it indicates that a measuring procedure not carefully standardized can easily lead to errors which can become important, specially in longitudinal studies. The impedance instruments used at the three centres were tested against each other and showed no differences in readings. In other studies differences between different instruments have been reported (Deurenberg et al. $1989 b$; Heitmann, 1990).

The present study shows that when standard procedures are used for the same subjects the relationship between total body impedance and FFM derived by densitometry is not different between research centres. Thus, differences between measured and calculated body composition derived from impedance formulas from the literature may be caused by differences in the reference population or by differences in the standardization procedure. Prediction formulas from the literature have to be applied with care. Ideally a prediction formula must be tested against a reference method for the subjects or population group under study before it can be applied.

This study was granted by Sandoz Nutrition, Den Bosch, The Netherlands.

\section{REFERENCES}

Baumgartner, R. N., Chumlea, W. C. \& Roche, A. F. (1989). Estimations of body composition from bio-electrical impedance of body segments. American Journal of Clinical Nutrition 50, 221-226.

Blanchard, J., Conrad, K. A. \& Harrison, G. G. (1990). Comparison of methods for estimating body composition in young and elderly women. Journal of Gerontology 45, 119-124.

Bland, J. M. \& Altman, D. G. (1986). Statistical methods for assessing agreement between two methods of clinical measurements. Lancet $\mathbf{i}, 307-310$.

Comroe, J. H., Forster, R. E., Dubois, A. B., Briscoe, W. A. \& Carlsen, E. (1977). The Lung - Clinical Physiology and Pulmonary Function Tests, 2nd ed., pp. 13-23. London: Year Book Medical Publishers.

Deurenberg, P., Leenen, R., van der Kooy, K. \& Hautvast, J. G. A. J. (1989a). In obese subjects the body fat percentage calculated with Siri's formula is an overestimation. European Journal of Clinical Nutrition 43, $569-575$.

Deurenberg, P., van der Kooy, K. \& Leenen, R. (1989b). Differences in body impedance when measured with different instruments. European Journal of Clinical Nutrition 43, 885-886.

Deurenberg, P., van der Kooy, K., Leenen, R., Weststrate, J. A. \& Seidell, J. C. (1991). Sex and age specific prediction formulas for estimating body composition from bio-electrical impedance: a cross validation study. International Journal of Obesity 15, 17-25.

Deurenberg, P., Weststrate, J. A. \& van der Kooy, K. $(1989 \mathrm{c})$. Is an adaptation of Siri's formula for the calculation of body fat percentage from body density in the elderly necessary? European Journal of Clinical Nutrition 43, 559-568.

Durnin, J. V. G. A. \& Womersley, J. (1974). Body fat assessed from total body density and its estimation from skinfold thickness: measurements on 481 men and women aged from 17 to 72 years. British Journal of Nutrition 32, 77-97.

Forbes, G. B. (1987). Human Body Composition. New York: Springer Verlag.

Heitmann, B. L. (1990). Prediction of body water and fat in adult Danes from measurements of bio-electrical impedance. A validation study. International Journal of Obesity 14, 789-802.

Lukaski, H. C. (1987). Methods for the assessment of body composition: traditional and new. American Journal of Clinical Nutrition 46, 437-456. 
Lukaski, H. C., Johnson, P. E., Bolonchuck, W. W. \& Lykken, G. E. (1985). Assessment of fat-free mass using bioelectrical impedance measurements of the human body. American Journal of Clinical Nutrition 41, 810-817.

McNeill, G., Fowler, P. A., Maughan, R. J., McGaw, B. A., Fuller, M. F., Gvozdanovic, D. \& Gvozdanovic, S. (1991). Body fat in lean and obese women estimated by six methods. British Journal of Nutrition 65, 95-103.

Moore, F. D., Olesen, K. H., McMurray, J. D., Parker, H. V., Ball, M. R. \& Boyden, C. M. (1963). The Body Cell Mass and Its Supporting Environments. Philadelphia: W. B. Saunders.

Raaij, J. M. A., Peek, M. E. M., Vermaat-Miedema, S. H., Schonk, C. M. \& Hautvast, J. G. A. J. (1988). New equations for estimating body fat mass in pregnancy from body density or total body water. American Journal of Clinical Nutrition 48, $24-29$.

Scheltinga, M. R., Jacobs, D. O., Kimbrough, T. D. \& Wilmore, D. W. (1991). Alterations in body fluid content can be detected by bio-electrical impedance analysis. Journal of Surgical Research 50, 461-468.

Schoeller, D. A., van Santen, E., Peterson, D. W., Dietz, W., Jaspan, J. \& Klein, P. D. (1980). Total body water measurements in humans with ${ }^{18} \mathrm{O}$ and ${ }^{2} \mathrm{H}$ labeled water. American Journal of Clinical Nutrition 33, 2686-2693.

Siri, W. E. (1961). Body composition from fluid spaces and density: analysis of methods. In Techniques for Measuring Body Composition, pp. 223-244 [J. Brozek and A. Henschel, editors]. Washington, DC: National Academy of Sciences.

Slaughter, M. H., Lohman, T. G., Boileau, R. A., Horswill, C. A., Stillman, R. J., van Loan, M. D. \& Bemben, D. A. (1988). Skinfold equations for estimation of body fatness in children and youth. Human Biology 60 , 709-723.

SPSS (1988). SPSS/PC+V2·0/V3·1, Base Manual. Chicago, Ill.: SPSS Incorporation.

Svendson, O. L., Haarbo, J., Heitmann, B. L., Gotfredsen, A. \& Christiaansen, C. (1991). Measurements of body fat in elderly subjects by dual-energy x-ray absorptiometry, bio-electrical impedance and anthropometry. American Journal of Clinical Nutrition 53, 1117-1123.

Tagliabue, A., Cena, H., Trentani, C., Lanzola, E. \& Silva, S. (1992). How reliable is bio-electrical impedance analysis for individual patients? International Journal of Obesity 16, 649-652.

Van der Kooy, K., Leenen, R., Deurenberg, P., Seidell, J. C., Westerterp, K. R. \& Hautvast, J. G. A. J. (1992). Changes in fat-free mass in obese subjects after weight loss: a comparison of body composition measures. International Journal of Obesity 16, 675-683.

Weststrate, J. A. \& Deurenberg, P. (1989). Body composition in children: proposal for a method for calculating body fat percentage from total body density or skinfold thickness measurements. American Journal of Clinical Nutrition 50, 1104-1115.

Widdowson, E. M., McCance, R. \& Spray, C. M. (1951). The chemical composition of the human body. Clinical Science 10, 113-125. 